\title{
The Time Theory Analysis and MATLAB Simulation of Control System Han-hong $\operatorname{Tan}^{1} \&$ Xiang Zhao ${ }^{2}$ \\ ${ }^{1}$ Department of Guangdong University of Science and Technology, DongGuan, 523083,China \\ ${ }^{2}$ Depaartment of School of Information and Communication of GUET, GuiLin, 541004, China
}

Keywords: unit step response, performance indicator, MATLAB, simulation

\begin{abstract}
The time-domain analysis in typical second order control system is given. The performance indicators of the unit step response system are calculated. Based on the MATLAB simulation, the unit step response performance indicators through the $\mathrm{M}$ function and Simulink dynamic structure diagram are obtained. The theory analysis and the simulation results are compared.
\end{abstract}

\section{Introduction}

The time-domain analysis method is used to solve the dynamic response of the system according to the Laplasse transform of differential equation system. The typical dynamic responses are included of the unit step response unit, the unit ramp response, the acceleration response and the unit impulse response etc.

One purpose of time domain analysis is to solve the performance indicators of the response system. The general performance indicators of step response include Peak Time (TP), Overshoot, Adjust Time (ts), and the Steady-state Error (ess).

\section{Theoretical Analysis}

The system which can be used to describe the two order differential equation is called second-order system. Its typical structure is shown in Figure 1.

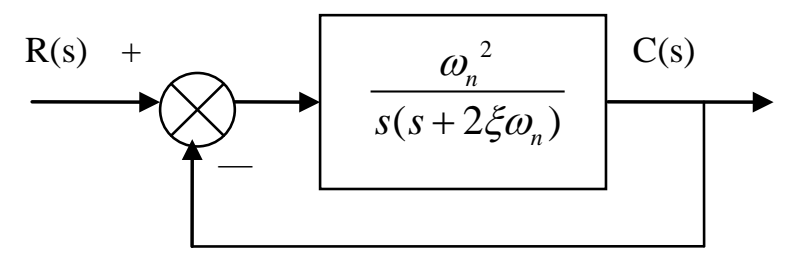

Figure 1: Typical structure of second-order system

Now the structure of second-order system is shown in Figure 2.

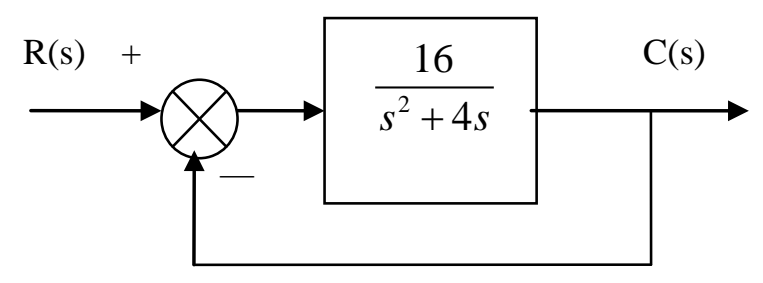

Figure 2: Structure of second-order system

The above system is the unit negative feedback system. The open-loop transfer function is $G(s)=\frac{16}{s^{2}+4 s}$.

The close - loop transfer function will be got. 


$$
\phi(s)=\frac{C(s)}{R(s)}=\frac{G(s)}{1+G(s) H(s)}=\frac{\frac{16}{s^{2}+4 s}}{1+\frac{16}{s^{2}+4 s}}=\frac{16}{s^{2}+4 s+16}
$$

The performance indicators and dynamic parameters of the system will be calculated under the unit Step function signal.

So the corresponding relation between the parameters and coefficient is shown as below.

$$
\left\{\begin{array}{l}
\omega_{n}^{2}=16 \\
2 \xi \omega_{n}=4
\end{array}\right.
$$

The absence of damping angle frequency and damping ratio is got as below.

$$
\omega_{n=4,} \xi=0.5
$$

So we will get the damping angle frequency.

$$
\begin{aligned}
\omega_{d}=\omega_{n} \sqrt{1-\xi^{2}}=4 * \sqrt{1-0.5^{2}}=3.46 \\
\beta=\arccos \xi=\arccos 0.5=60^{\circ}=\frac{\pi}{3}=\frac{3.14}{3}=1.05
\end{aligned}
$$

The dynamic performance indicators of the system will be got as follows.

(1) Delay Time:

$t_{d}=\frac{1+0.7 \xi}{\omega_{n}}=\frac{1+0.7 * 0.5}{4}=0.34$

(2) Raise Time:

$t_{r}=\frac{\pi-\beta}{\omega_{d}}=\frac{3.14-1.05}{3.46}=0.6$

(3) Peak Time:

$t_{p}=\frac{\pi}{\omega_{d}}=\frac{3.14}{3.46}=0.91$

(4) Overshoot:

$\sigma \%=e^{-\frac{\pi \xi}{\sqrt{1-\xi^{2}}}} * 100 \%=e^{-\frac{3.14 * 0.5}{\sqrt{1-0.5^{2}}}} * 100 \%=e^{-1.81} * 100 \%=\frac{1}{e^{1.81}} * 100 \%=16.3 \%$

(5) Setting Time

$t_{s}=\frac{3.5}{\xi \omega_{n}}=\frac{3.5}{0.5 * 4}=1.75$

( The error band corresponding to $5 \%$ )

$t_{s}=\frac{4.5}{\xi \omega_{n}}=\frac{4.5}{0.5 * 4}=2.25$

( The error band corresponding to $2 \%$ )

(6) Peak Magnitude

$\mathrm{MP}=(1+\sigma) * 1=(1+0.163) * 1=1.163$

If input signal is unit step function, the output of second order under-damped system $\quad(\xi<1)$ is shown in Figure 3. 


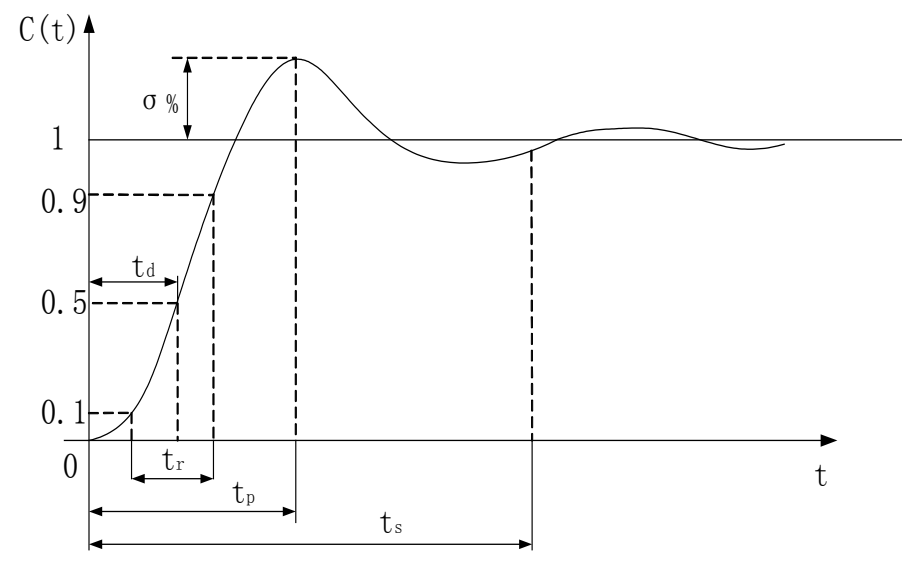

Figure 3: Unit step response of second order under-damped system

\section{Simulation Based on MATLAB Command}

In order to analyze time domain performance of control system, the following commands are entered in the MATLAB7.0 command window.

$>>$ num $=[16]$;

$>>$ den=[1 4 l 0$]$;

$>>$ sys $=\operatorname{tf}($ num,den)

Transfer function:

16

$\mathrm{s}^{\wedge} 2+4 \mathrm{~s}$

$>>$ closys $=$ feedback(sys, 1$)$

Transfer function:

16

$\mathrm{s}^{\wedge} 2+4 \mathrm{~s}+16$

>> step(closys)

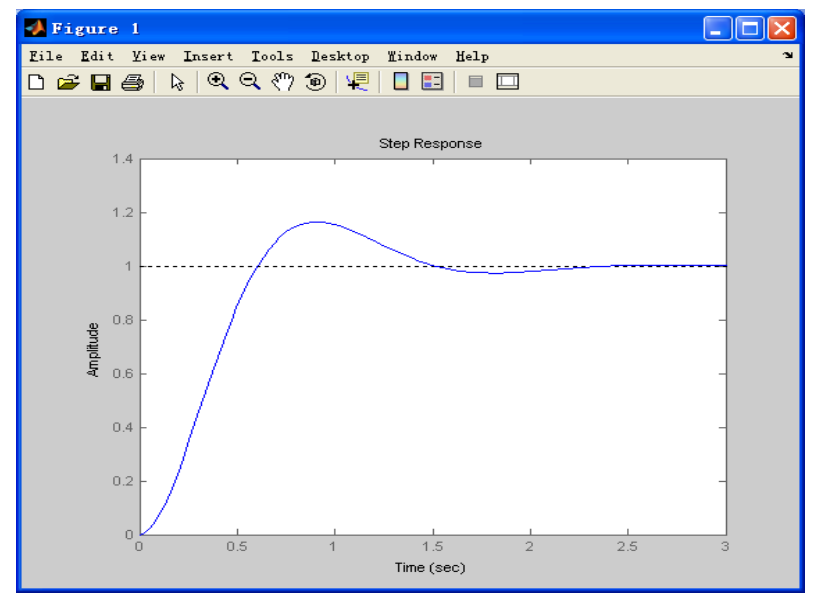

Figure 4: Unit step response of second order system based on MATLAB

$>>[\mathrm{y}, \mathrm{t}]=$ step(closys);

$>>$ [mp,tp,ess,b1,b2,sigma,n,pusi,T,f] $=\operatorname{targ}(\mathrm{y}, \mathrm{t})$

$\mathrm{mp}=1.1630$

tp $=0.9110$

ess $=-0.0028$

$\mathrm{b} 1=0.1603$

$\mathrm{b} 2=0.0016$

sigma $=15.9813$ 


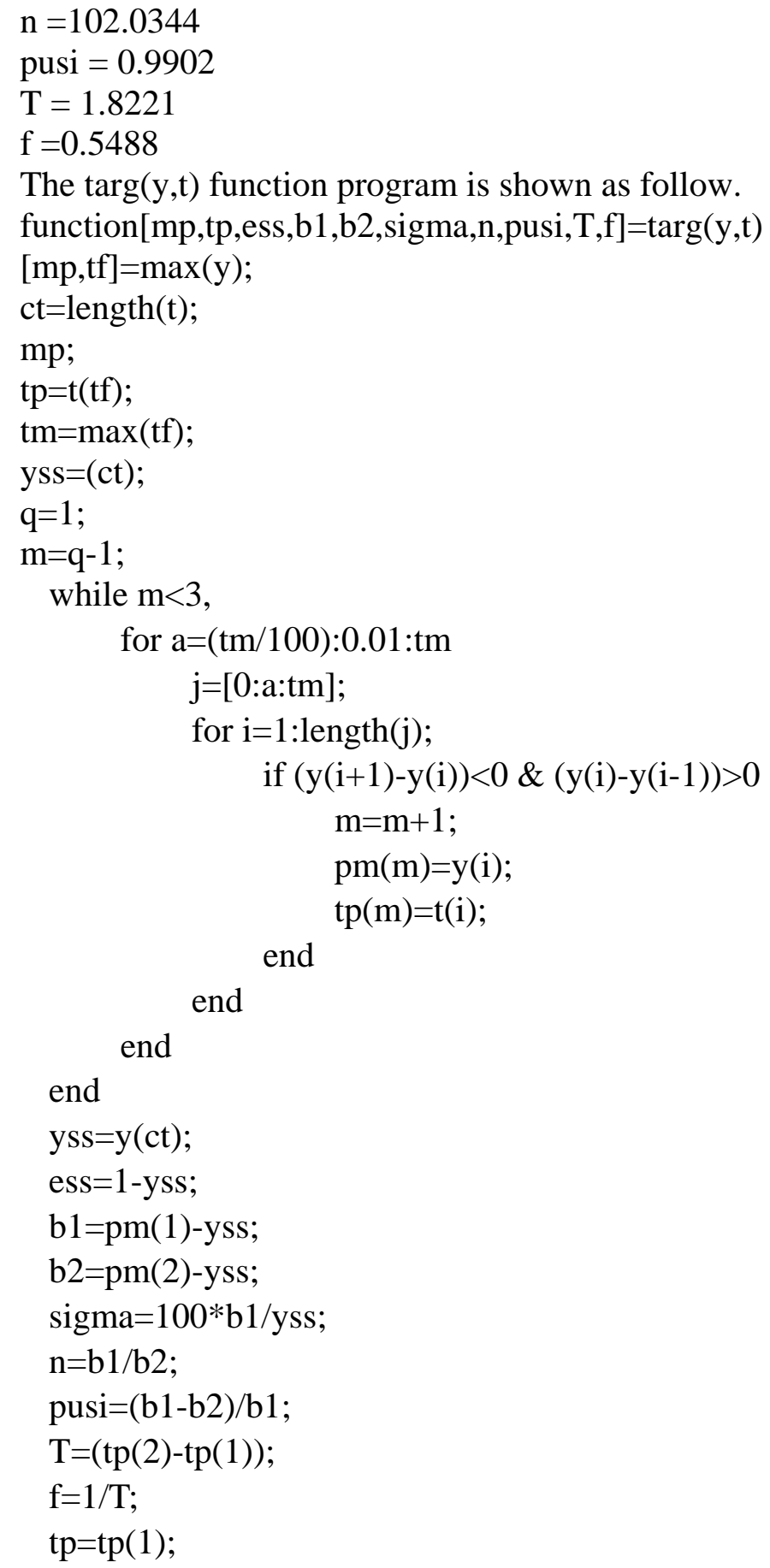

The symbols meanings of above program are given as follows. MP is Peak Magnitude; TP is Peak Time; ESS is Steady-state Error; B1 is Overshoot of first peak; B2 is Overshoot of second peak; Sigma is overshoot of step response; $n$ is attenuation of step response; Pusi is decrement of step response; $\mathrm{T}$ is period; $\mathrm{F}$ is frequency.

\section{Simulation Based on Simulink of MATLAB}

The Simulink dynamic structure diagram of second order system based on MATLAB is given as figure 5 . And it is named as "erjie". 


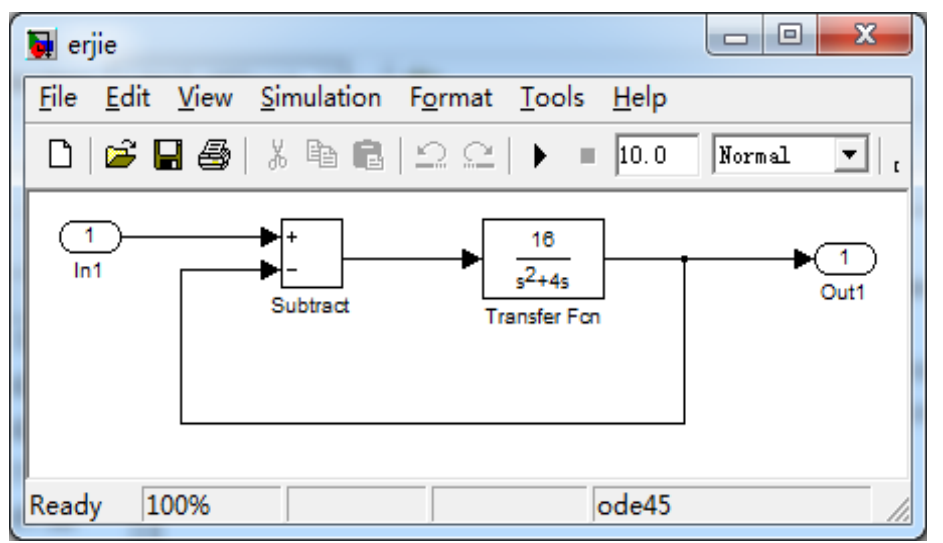

Figure 5: Simulink dynamic structure diagram of second order system based on MATLAB Parameters of Transfer Fcn are set as figure 6.

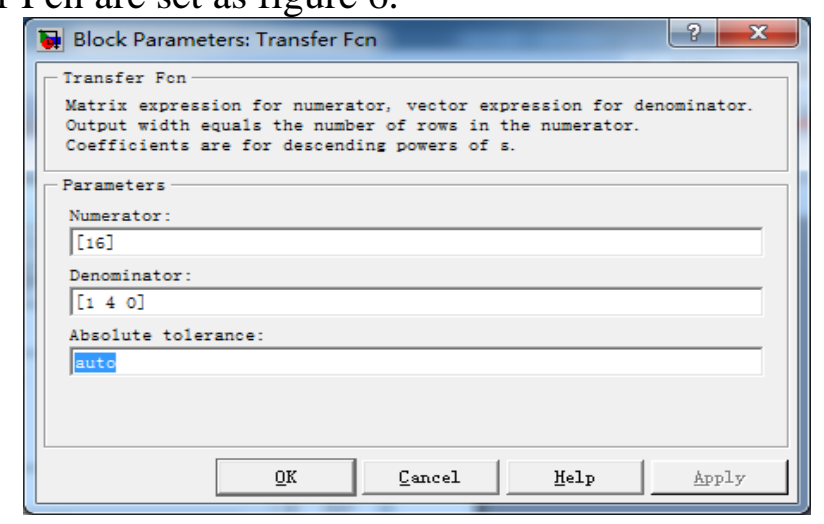

Figure 6: Parameters setting of Transfer Fcn

The following commands are entered in the MATLAB7.0 command window.

$>\quad[a, b, c, d]=l i n m o d(' e r j i e ')$

$\mathrm{a}=$

$-4 \quad-16$

10

$\mathrm{b}=$

1

0

$\mathrm{c}=$

$0 \quad 16$

$\mathrm{d}=$

0

$>$ sys=ss(a,b,c,d);

$>>$ figure(1)

$>>$ step(sys) 


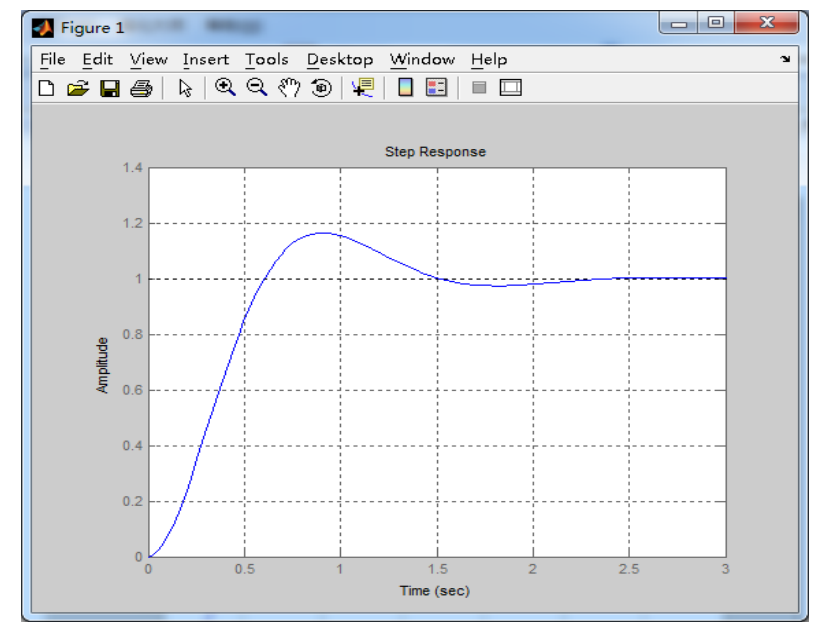

Figure 7: Unit step response of second order system based on Simulink

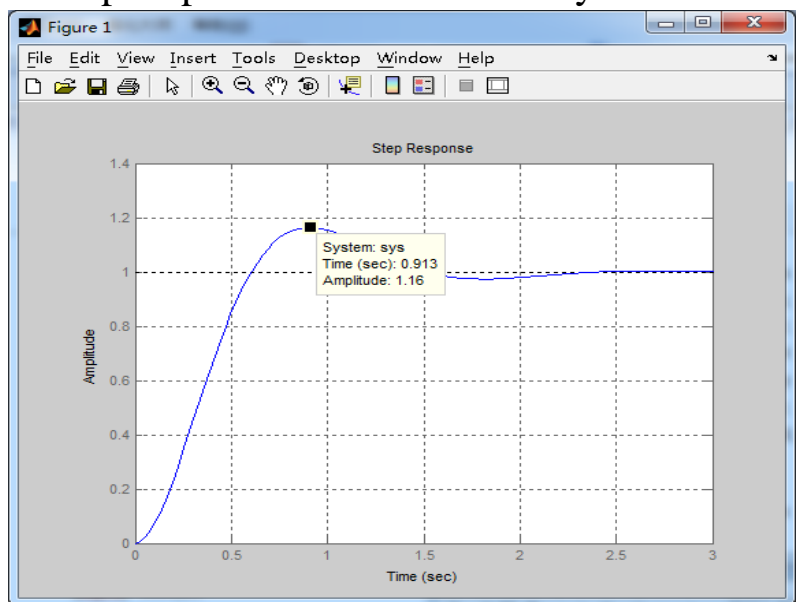

Figure 8: Unit step response of second order system performance based on Simulink $>>$ figure(2)

$>>$ impulse(sys)

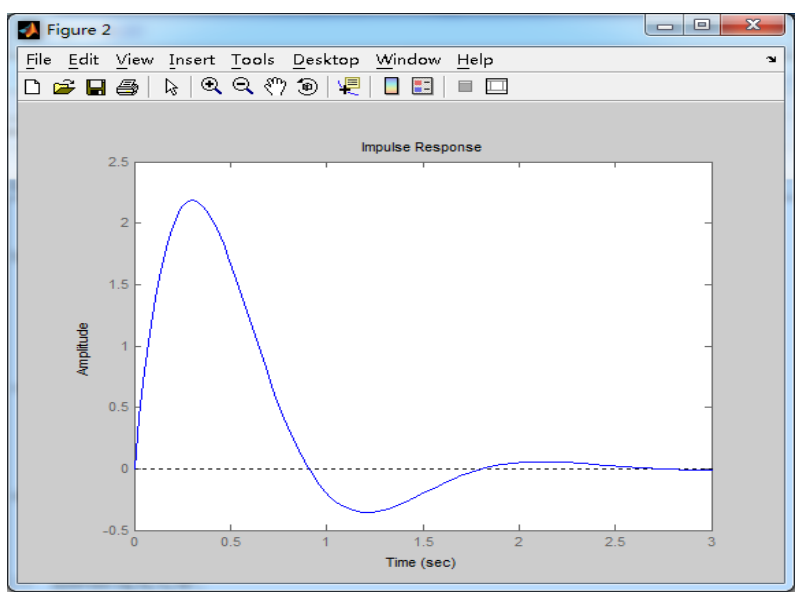

Figure 9: Unit impulse response of second order system performance based on Simulink

From figure 8 , it can be seen that the unit pulse response peak time $\mathrm{TP}=0.913$ second and peak Magnitude MP=1.16.

\section{Conclusions}

According to the simulation result, we can see that $\mathrm{MP}=1.1630, \mathrm{TP}=0.9110, \mathrm{~B} 1=0.1603$. According to the theory analysis above, we know that $\mathrm{MP}=(1+\sigma) * 1=(1+0.163) * 1=1.163$, $t_{p}=0.91 \mathrm{~S}, \quad \sigma \%=16.3 \%=0.16$. MATLAB simulation Results are consistent with theoretical analysis. MATLAB simulation verifies the theoretical analysis. 
The time-domain analysis in typical second order control system is given. The performance indicators of the unit step response system are calculated. Based on the MATLAB simulation, the unit step response performance indicators through the $M$ function and Simulink dynamic structure diagram are obtained. The theory analysis and the simulation results are compared. This paper has good auxiliary function to use and study the typical second order control system.

\section{References}

[1] Yan-kui Chen. Traffic lights control system based on the single chip [J]. Journal of Chongqing University of Science and Technology (NATURAL SCIENCE EDITION), December 2007, ninth volume fourth issue: 59-60

[2] Jing Zhang .AT89S8252 single chip microcomputer in intelligent device using [J]. Journal of Chongqing Institute of Technology,20(5):70-72. 2006.

[3] [Online]Available:http://www.iject.org/vol2issue3/2/rashmi.pdf. 2011

[4] Quan-li Li. Principle and application of single chip microcomputer technology [M]. Beijing: Higher Education Press, 2004

[5] Zheng-xiong Jiang, Qiu-ling Jia \& LI Guang-wen. Asymptotic consensus protocols of multiple nonlinear agent network [J]. Control Engineering of China, 2008, 15(4):434-436.

[6] SU H S, CHEN G R, WANG X F. Adaptive second-order consensus of networked mobile agents with non-linear dynamic[J]. Automatic, 2011, 47:368-375.

[7] C. M. Johnstone, K. Nielsen, T. Lewis, A. Sarmento, and G. Lemonis, EC FPVI co-ordinated action on ocean energy: A European platform ford sharing technical information and research outcomes in wave and tidal energy systems, Renewable Energy, vol. 31, pp. 191 - 196, 2006.

[8] S. E. Ben Elghali, M. E. H. Benbouzid, and J. F. Charpentier, Marinetidal current electric power generation technology: State of the art and current status, in Proc. IEEE Int. Electr. Mach. Drives Conf. , Antalya, Turkey, May 2007, vol. 2, pp. 1407 - 1412.

[9] M. M. Hand, K. E. Johnson, L. J. Fingersh, and A. D. Wright, Advanced control design and field testing for wind turbines, Nat. Renewable Energy Lab. (NREL), NREL/CP-500-36118, 2004.

[10] Seif Eddine Ben Elghali , Mohamed El Hachemi Benbouzid, Tarek Ahmed-Ali, High-Order Sliding Mode Control of a Marine Current Turbine Driven Doubly-Fed Induction Generator, IEEE Journal of Oceanic Engineering, Vol.35.NO.2, April, 2010

[11] John J. D’Azzo and Constantine H. Houpis \& Stuart N. Sheldon , Linear Control System Analysis and Design With MATLAB : Conventional and Modern, Fifth Edition, Revised and Expanded

[12]Seiichiro Katsura, Yuichi Matsumato, and Kouhei Ohnishi, Analysis and Experimental Vali dation of Force Bandwidth for Force Control, International Conference on Industrial Technol ogy, IEEE, pp. 796-801, 2003. 